\title{
8 Participatory Propaganda: The Engagement of Audiences in the Spread of Persuasive Communications
}

\author{
Alicia Wanless and Michael Berk
}

Rapidly evolving information communications technologies (ICTs) and increased connectivity to online sources have drastically altered the ways individuals engage in the public information domain and, in turn, become influenced by it. As citizens become increasingly plugged-in, a savvy propagandist can acquire enhanced means of swaying opinions around the world by combining tech-enabled formats of persuasive content, automated dissemination and audience engagement in content propagation. In addition, by obfuscating the origins of propagandistic content through audience participation via the internet and social networks, the propagandist can also increase its receptivity and influence effects. For example, people tend to find recommendations from their personal social network more credible than others (Nielson, 2015). Such subtle mass persuasion, through and by means of personal networks, is problematic in liberal democracies founded on the premise that freedom of choice by citizens on political matters is expected to inform public decision-making and power structures (Lippman, 1922; Irwin, 1919; Marlin, 2011).

This paper is broken into three sections. In the first, a multidisciplinary literature review aggregates individual studies published recently that analyze the known digital, behavioral and psychological tactics available to propagandists aiming to engage target audiences online. Extensive research conducted by scholars over recent years on new ICT tools, social networks, influence tactics and their manifested effects on consumers of online information, including their political choices, has been instrumental in acquiring the first appreciation for the scale, complexity and social repercussions of modern persuasive communications - what we called "participatory propaganda." In the second section, the paper draws on original research conducted during the 2016 US presidential elections to analyze how Trump supporters applied these tactics to engage Facebook followers in the promotion of persuasive content, thus encouraging them to become propagandists themselves. In the conclusion, the research results are placed into the broad context of the emerging information environment describing possible repercussions for citizens' political engagement and arguing that further modelling of digital propaganda is required to better understand the risks to liberal democracy associated with using such techniques. 


\subsection{Modern Propaganda and the Evolution of Its Participatory Model}

Propaganda is a much-contested term applied in many contexts under different names either to explain and justify more acceptable forms of public influence, or to denigrate and dismiss similar efforts done by perceived opponents. This difficulty in defining propaganda stems in part from its complicated relationship with liberal democracies where public opinion is expected to influence political decision-making and the act of manipulating it calls into question the agency of voters and the democratic system itself.

Traditionally, propaganda has been described as the use of persuasive information to manipulate a target audience into a behaviour desired by the propagandist (Bernays, 1928; Lasswell, 1948; Ellul, 1965; Marlin, 2013; Jowett \& O’Donnell, 2015). In this topdown communications model, the sender-receiver roles were typically static with the propagandist (government, corporate, military) issuing persuasive messaging to achieve a specific outcome among the target audience (general public). Early pioneers in the field of public relations, who also led American propaganda activities during World War I, saw how easily public opinion could be swayed and, yet, saw domestic propaganda as an acceptable tool for the management of popular views (Bernays, 1928; Lasswell, 1934; Lippmann, 1922). Around the same time, propaganda began to acquire a pejorative connotation as it was "associated mainly with totalitarian regimes and war efforts" and "was perceived as a threat to liberal democracies" (Ross, 2002, p. 17). To differentiate between acceptable forms of influence, domestic- and foreignbound, other terms such as public affairs or public relations (Moloney, 2006), or public diplomacy or information operations (Garrison, 1999) were introduced.

This classic understanding of propaganda, however, must be adapted for the Digital Age. With the internet and social media, the traditional separation between "the propagandist" and "target audience" is rapidly blurring, with the latter beginning to play a more significant role in spreading propagandistic content and influencing others through personal networks - a more dangerous development since people are more likely to believe those familiar to them (Garrett \& Weeks, 2013) or those they view as influential (Turcotte et al., 2015).

In this context, a new concept for the understanding of modern propaganda is suggested - participatory propaganda - that adapts the traditional definition proposed by Jowett \& O'Donnell ${ }^{29}$ to the Digital Age's technological capabilities allowing modern propagandists, at least in theory, to exert a qualitatively greater influence.

29 The original definition of propaganda by Jowett \& O’Donnell reads "Propaganda is the deliberate and systematic attempt to shape perceptions, manipulate cognitions, and direct behavior to achieve a response that furthers the desired intent of the propagandist.” See Jowett \& O’Donnell, 2015, p. 7. 
Participatory propaganda is the deliberate and systematic attempt to shape perceptions, manipulatecognitions, and direct behaviour of a targetaudiencewhileseeking to co-opt its members to actively engage in the spread of persuasive communications, to achieve a response that furthers the desired intent of the propagandist.

The nuanced difference from the traditional interpretation of propaganda lies in the fact that in the Digital Age modern technologies allow propagandists to not just push a message, but get audience "buy-in" through content that triggers engagement with it. ${ }^{30}$ The ease and convenience of social media offer users a psychologically rewarding and socially acceptable opportunity to "take action" online, empowering them to influence their reality with a few mouse clicks (at least to the extent the size of their network allows it). This superficial and illusory influence, which nonetheless may appear quite real to users, transforms them from passive consumers of propaganda into active campaigners. Through this engagement, propagandists can amplify their message, and by obfuscating its provenance, increase its receptivity among wider populations.

From a methodological perspective, participatory propaganda transcends a traditional, vertical and unidirectional form of persuasive communication where a clearer distinction, but also connection, between a content originator and target audience existed. The diffusion of interconnected networks abetted by users' interconnectivity to and across various online platforms creates a borderless network for distribution and amplification of persuasive content where each "object" of influence (a target individual or group) can, and does, also become the new "subject" of content production and distribution in a "snowball" fashion. In this dynamic environment, an original message would continue to trigger, reinforce, or exacerbate pre-existing sentiments associated with it, prompting its consumers to actively engage in its propagation, both on and offline, for as long as it continues to reflect their entrenched values and perceptions. Whether modified or not by the consumer, the core message often remains intact, acquiring a "new life" in each new wave of content dissemination. Easy access to online monitoring tools allows the original propagandist to follow and assess the spread of their messaging, adapting strategies in a constant feedback loop and inserting additional content, as and if required.

Participatory propaganda offers the ability to truly dominate the information space through volume of messaging, delivered through a mix of real people and automated accounts, effectively making it difficult to discern where fake ends and authenticity begins.

30 In modern practice of campaign management, the evaluation of a campaign's effectiveness commonly relies on engagement statistics offered by social media platforms. These statistics are presented as a manifestation of the message's effectiveness, which of course could be misleading since it often demonstrates the potential spread of messaging but not its actual effect on an audience, if it has any. Sharing of content and commenting, on the other hand, could be perceived as a truer engagement, unless it is accomplished through unauthentic behaviour (e.g. bots). 
The analysis of modern political campaigns with their increasing reliance on social networks demonstrates the case in point. While many campaigns still push messages as traditional propaganda, as defined by Jowett and O'Donnell, namely the "deliberate, systematic attempt to shape perceptions" (e.g. popular opinions of Trump supporters) such that it "directs behaviour to achieve a response" (e.g. support for Trump in the form of online participation and voting) furthering "the desired intent of the propagandist" (e.g. the Trump campaign), they increasingly acquire the characteristics of a participatory propaganda model. This research, based on analyses of recent academic studies and the US presidential campaign by Donald J. Trump, identified six digital tactics for engaging a target audience online to draw them into active dissemination of persuasive messaging. The order in which these tactics are presented below corresponds to the order of steps a propagandist would take to develop and disseminate the original persuasive messaging.

\subsubsection{Hyper-Targeted Audience Analysis}

Using behavioural advertising methods, propagandists acquire information about their target audience's activities online, which enables them to position highly targeted ads in front of users (Matthew, 2017). Trackers that facilitate the collection of this information were found on 114 websites supporting Trump during the 2016 election (Albright, 2016a). This information can be used to segment target audiences by psychographic categories (Psychometric Centre, 2017), providing a propagandist with an extremely accurate assessment of user preferences and what might provoke them into action (Cohen, 2017). Social networks facilitate the application of this knowledge to targeted ad placement (Solon, 2017), as was demonstrated by the Trump campaign (Nix, 2016). After targeted audience analysis is conducted and profiles created, the creation of provocative content ensues.

\subsubsection{Provocative Content}

Provocative content aims to appeal to pre-existing user beliefs and perceptions, triggering an emotional reaction in return, which is then expected to manifest itself through engagement both on and offline. At least three types of content aimed at provoking a response among target audiences were used by Trump supporters: fake news, memes, and data leaks.

Fake News. Facebook defined fake news as "articles that purport to be factual, but which contain intentional misstatements of fact with the intention to arouse passions, attract viewership, or deceive." (Weedon et al., 2017). Since lies spread faster online than the truth (Silverman, 2015), fake news has become a global problem (Connolly et al., 2016). Conspiracy theories, often a feature of fake news, reduce complex issues 
to "binary opposition, simplifying - and misrepresenting - the political space," (Moore, 2015, p. 9) and a person's degree of partisanship is linked to their likelihood of believing conspiracy theories or fake news (Frankovic, 2016). Governments and non-state actors alike are spreading disinformation online (Weedon et al., 2017), including Trump, who spread fake news during the campaign (Maheshwari, 2017). When such content was shared by known and trusted opinion-leaders on Facebook, in essence legitimizing it, they tended to influence audience perspectives (Turcotte et al., 2015). Indeed, stories favouring Trump were shared nearly four times more than those supporting Clinton (Allcott \& Gentzkow, 2017).

Memes are often humorous phrases, images or videos that are copied or adapted with slight variations and then shared online (Blackmore, 2000). During the 2016 election, Facebook groups sprang up dedicated to sharing "dank memes" (Hsu, 2016) and a controversial Silicon Valley tech entrepreneur funded a "meme factory" to support Trump (Hern, 2016). So-called "meme battalions" created visual content that "relentlessly drew attention to the tawdriest and most sensational accusations against Clinton, forcing mainstream media outlets to address topics - like conspiracy theories about Clinton's health - that they would otherwise ignore” (Schreckender, 2017).

Memes reduce the public policy debate to shallow sound bites and ridicule stripped of contextualized understanding of available political choices (McClure, 2016). This contributes to 'media endarkenment' reducing complex political issues to simplified entertainment and misinformation (Lazitski, 2014).

Leaks have long played a role in American political propaganda (Castronovo, 2014). According to the Oxford Dictionary, a leak is the "intentional disclosure of secret information” (2017). During the 2016 election, Clinton was dogged by several leaks, which could have been one factor affecting her standing in public opinion polls (Enten, 2016). These included the hacking of her Chief of Staff John Podesta's emails (Frank, 2016), the leaking of comments she made about Bernie Sanders supporters (Democracy Now, 2016), and the continued FBI investigations around the private email server Clinton used while serving as Secretary of State (exposed through a hack), which hampered her campaign (Williams, 2016).

Eliciting an emotional response among a target audience, provoking them into active participation, is an effective method of target audience engagement. In particular, this is true if the content is fed through existing channels where an audience already receives associated information, such as an online echo chamber.

\subsubsection{Echo Chambers}

Drawing from the insights gained in hyper-targeted content analysis, a propagandist can identify online echo chambers with specific audiences who can then be targeted with provocative content to which they are most likely to react. An online echo chamber 
is a digital space where content reflecting a specific point of view reverberates, exposing those within it to only that one prevailing perspective. Digital technologies enable the quick creation of echo chambers or filter bubbles (Breitenbach, 2017), in part through algorithms that sort information (Bakshy et al., 2015), but more so by the choices individuals make about content consumption (Bessi et al., 2016; Grömping, 2014). Once inside an echo chamber, a user is fed content fitting pre-existing views and preferences, such as political party affiliation (Wall Street Journal, 2016).

Echo chambers identified during the 2016 election were strengthened by a growing animosity between political camps (Thompson, 2016), as well as a lack of media trusted by both Republicans and Democrats (Pew, 2016a), and thus information exchange was hindered across party lines (Mitchell et al., 2016). Moreover "political echo chambers not only isolate one from opposing views, but also help to create incubation chambers for blatantly false (but highly salient and politicized) fake news stories" (Pennycook et al., 2017).

Echo chambers supporting Trump shared fakes news during the election (Dreyfus, 2017; BBC, 2016), with some hyper-partisan, right-wing Facebook communities feeding followers 38\% fake content (Silverman et al., 2016).

\subsubsection{Manipulating Feed and Search Algorithms}

This step relates to positioning and boosting provocative content in front of users by manipulating important online algorithms. Internet giants, such as Facebook (Facebook, 2017a, 2017b) and Google (Google, 2017), use algorithms to provide users with content they think is wanted. Search returns have been found to sway voter decisions (Epstein \& Robertson, 2015) and algorithms enable echo chamber development (Barret, 2016). Learning and understanding how these platforms operate both through openly available information and experimentation may allow a propagandist to ensure their provocative content appears higher and more often in returns, or in front of a user.

Algorithms had a role in the 2016 elections. Fake news supporting Trump trended on Facebook through algorithms (Lee, 2016), whereas Google search autocompletes and returns favoured Trump, spreading false information with a far-right bias (Solon \& Levin, 2016).

Google Search algorithms can be gamed in at least two ways:

Hyperlinking and Seeding of Content: Posting content, such as fake news, on multiple websites and linking back and forth between sources helps boost content in Google search returns (Moz, 2107), and if nothing else, can bury opposing information from appearing in the first pages of returns. Indeed, in one study using hyperlink network analysis pro-Trump websites were found to be choking out mainstream media (Albright, 2016b). 
Botnets and Automated Posting: Lobby groups (Monbiot, 2011), governments (Dhami, 2011), and businesses (Kabin, 2013) are among the many who attempt to create the illusion of grassroots support by using fake social media accounts to distort the information space for strategic purposes. Posting fake comments and reviews aims to harness the cognitive bias of "social proof" (Ambled \& Bui, 2011), whereas botnets (and heavily automated posting) can manipulate algorithms. For example, Twitter bots gamed Google's algorithm for displaying "real time news" into promoting disinformation during a 2010 senate election in Massachusetts (Mustafaraj \& Metaxas, 2010).

During the 2016 election, pro-Trump automated Twitter accounts dominated discussion about the US election 5 to 1 over pro-Clinton messaging, and "strategically colonized pro-Clinton hashtags," according to Oxford Internet Institute research (Kollanyi \& Howard, 2016). Bots also accounted for nearly one-fifth of online discussion about the election (Bessi \& Ferrara, 2016), negatively affecting political discourse by drowning opposing views and elevating Trump-related returns in Google search ranking. ${ }^{31}$

\subsubsection{Encouraging Followers to Action}

Once inside echo chambers, followers can be encouraged through posts and email distribution lists (Albright, 2016a; Plouffe, 2010) to participate in the spread of propaganda, including: sharing messages; co-opting or borrowing influencer accounts to share content (Katalenas, 2016); or encouraging trolling (Cheng et al., 2017; Buckels et al., 2014) to stifle debate.

To many, Trump is a troll (Silver, 2015; Offman, 2016; Lapowsky \& Marshall, 2017), but he was also supported by a legion of online trolls during the election (Marantz, 2016), spreading disinformation (Kang, 2016; Gallucci, 2016) and attacking Clinton supporters online (Chmielewski, 2016). Some online communities, such as the United States Freedom Army (who believes the left is engaging the right in a civil war) offered its members a monthly directive on actions to take on Twitter, and elsewhere in the spread of their content and support for Trump (Lotan, 2016).

31 This online domination through automation led researchers to coin a new term for explaining computer-assisted propaganda techniques - the computational propaganda. See, Woolley, S.C. \& Howard, P.N. eds., 2018. Computational propaganda: political parties, politicians, and political manipulation on social media. Oxford: Oxford University Press. 


\subsubsection{Using Traditional Media}

Media play a critical role in furthering political agendas (Wodak, 2013; Engel \& Wodak, 2009; Engel \& Wodak, 2012); after all, "the media are a key element in the construction of public understanding” (Philo, 2008, p. 539). Rates of a politician's media coverage correlate to popular support levels (Vliegenthart et al., 2012) and Trump was consistently mentioned more on television, online, and social media (Wanless, 2016). By the start of the primary election campaign in early 2016, Trump had been enjoying "more nightly news coverage than the entire Democratic field combined" (Borchers, 2015). Media coverage can be earned in at least three ways:

- Trending Online - generating media coverage simply by occupying top positions in social media (which can also be distorted by using bots and automated posting).

- Staging a Scandal - populist politicians are particularly adept at gaining media attention, provoking opposition to attack, then distorting ensuing debate to position themselves as victims not tolerated by a biased system.

- Commune with the news - media politicians and online communities have a deeply interconnected relationship, creating a distinct and insulated media system which uses social media to spread hyper-partisan perspectives.

\subsubsection{Assess, Modify and Repeat}

Strategic communicators can rely on multiple technological means to monitor, assess and evaluate the quality and extent of reach acquired in relation to each original message. The data analysis is used to modify messaging to ensure greater uptake or fine-tune the approach to specific target audiences.

As these studies demonstrate, many of these techniques when combined could be used to encourage followers and co-opt audiences into active participation, becoming propagandists for a cause and thus deliberately working to persuade their own personal networks too. To evaluate the extent of their application during the US presidential elections, an original study of Facebook pro-Trump pages was conducted to assess how audiences might have been engaged in the creation and distribution of persuasive political messaging.

\subsection{Modelling Participatory Propaganda}

\subsubsection{Methodology and Data}

The study included social network and content analyses undertaken on 17 Facebook pages, using data related to a month-long period leading up to the 2016 election ( 7 October to 7 November). These pages included three that supported Trump during the 
election, as well as seven conservative-leaning and seven liberal-leaning media outlets. The digital tactics outlined in the previous section were used as a frame for investigation.

Social Network Analysis (SNA) has shown to be an effective method to study online group dynamics, information diffusion processes, and political polarisation in social media (Gruzd \& Roy, 2014; Gruzd \& Tsyganova, 2015; Scott, 1988, 2011). Facebook pages and groups have been analysed to identify echo chambers (Grömping, 2014; Bakshy et al., 2015; Del Vicario et al., 2016). And content analysis has been used to assess right-wing populist rhetoric in media (Bos et al., 2010, 2011; Sheets et al., 2016).

Facebook was selected for this research as $79 \%$ of American adults who use the internet also use this social network (Pew, 2016b), making it the most popular and thus representative social media for studying politics in the US.

The data collection process was executed using Facebook Graph API through Netvizz (Rieder, 2013), and only publicly available data was used. Network visualisations were created using the open-source SNA software, Gephi (Bastion et al., 2009).

The pages analysed are as follows:

Table 8.1: Facebook pages analysed.

\begin{tabular}{lll}
\hline Trump Supporters & Right-Leaning Media & Left-Leaning Media \\
\hline Citizens for Trump & Breitbart & CBS News \\
Eagle Rising & The Glenn Beck Program & CNN \\
Wake Up \& Reclaim America & Fox News & MSNBC \\
& Infowars & NPR \\
& The Sean Hannity Show & The New York Times \\
& The Drudge Report & PBS \\
& The Blaze & The Washington Post \\
\hline
\end{tabular}

The three pro-Trump pages were chosen as a sample of those supporting his candidacy, with one showing its open support through the name (Citizens for Trump), another having been found spreading fake news (Silverman et al., 2016) supporting Trump (Eagle Rising), and a third standing out as a node in initial, exploratory network analysis (Wake Up \& Reclaim America).

Drawing from a Pew Research Centre survey on Political Polarization and Media Habits (Mitchell et al., 2016), seven media outlets trusted consistently by respondents who self-identified as liberal or conservative were selected. One substitute was made on the conservative-leaning side, which was Infowars, given the role it played in the election (Finnegan, 2016). Media pages were used to assess how pro-Trump pages were engaging with news outlets. 


\subsubsection{Facebook Page Like Networks}

An initial "seed" page liking other pages revealed a directed network of pages linked to it on Facebook, which was visualised using Gephi. The data in this pull also included information regarding page categories, follower numbers, and rates of engagement.

\subsubsection{Facebook Page Posts}

All of the posts made by these pages during the month leading up to the election were also collected, including information regarding the type of post, engagement rates, and embedded links.

This data was analysed to answer the following questions:

- Did pro-Trump pages share provocative content such as fake news, memes, and data leaks?

- Did pro-Trump pages constitute an echo chamber?

- Was content shared on pro-Trump pages posted across multiple websites? And how was this content reflected in Google search returns?

- Were followers of pro-Trump pages encouraged to action?

- How did pro-Trump pages engage with media outlets?

\subsection{Findings}

\subsubsection{Pro-Trump Pages Shared Different Kinds of Provocative Content, Such as Fake News, Memes, and Data Leaks}

Fake News. The links shared to the three Trump-supporting pages were mostly nonmainstream media. On average, link posts comprised 53.22\% of updates made by the pro-Trump pages. Eagle Rising shared more links than the other two (83.25\% of posts), with nearly half of those links (45.4\%) pointing to the page's own website eaglerising. com, which contains coverage speculating on connections between Clinton, terrorists and Nazis, ${ }^{32}$ for example, and the Clinton campaign's alleged use of psychological warfare (which in turn points back to another site shared by these pages called ipatriot.com)..$^{33}$

After Breitbart, the most shared domain to Citizens for Trump was gatewaypundit. com, a blog that has posted many questionable articles on Hillary Clinton, including

32 See: https://eaglerising.com/23441/the-real-link-between-hillary-clinton-terrorists-and-nazis/ 33 See: http://eaglerising.com/36390/how-the-clinton-campaign-is-using-psychological-warfare/ 
that she secretly called for Trump's assassination, ${ }^{34}$ had suffered a brain seizure, ${ }^{35}$ and that she had a gum and immune disorder. ${ }^{36}$ During the period between 7 October to 7 November 2016, Citizens for Trump shared 13 Gateway Pundit articles, accounting for 4.32\% of all link posts, including one speculating on Clinton's health that enjoyed 319 shares on Facebook. ${ }^{37}$ Wake Up \& Reclaim America also shared 14 Gateway Pundit articles, including a post suggesting Clinton was involved in having Supreme Court Justice Scalia assassinated. ${ }^{38}$

Memes. Drawing from a similar study of Breitbart posts (Renner, 2017), memes were counted by the total number of photo posts made by the pro-Trump pages. Memes account for a considerable number of posts on community Facebook pages such as Wake Up \& Reclaim America. In analysis of 1,330 posts made by Wake Up \& Reclaim America in the month leading up to the 2016 election, nearly half were image posts. Nearly two-thirds of those photo posts were shared by the page administrator from other Facebook user posts, pages or groups, such as Liberal Wackadoodles, indicating spread through a wider community. Memes were also shared by Eagle Rising (14.79\%) and Citizens for Trump (26.62\%).

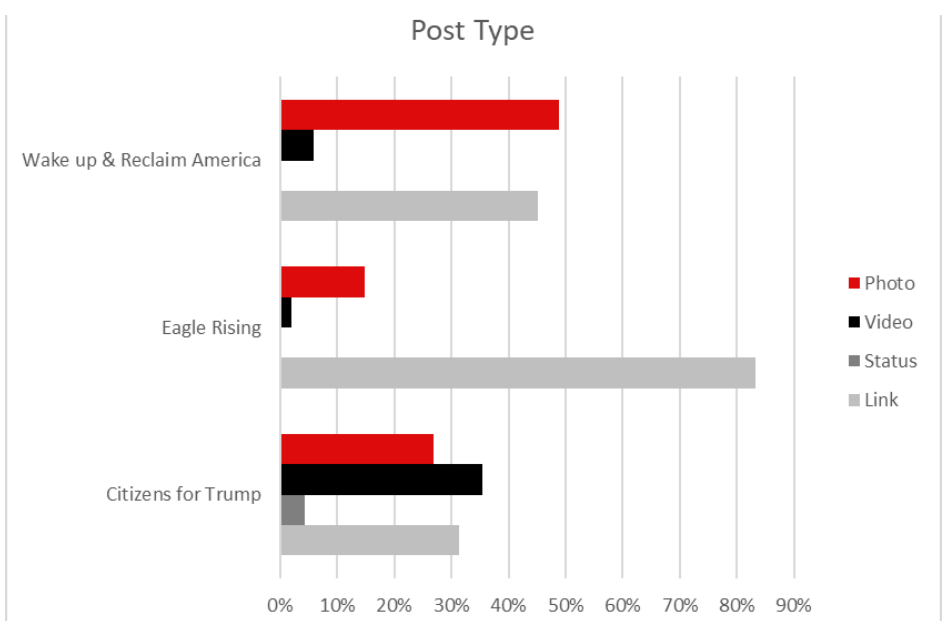

Figure 8.1: Post type by pro-Trump Facebook pages.

34 See: http://www.thegatewaypundit.com/2016/09/hillary-clinton-dog-whistle-call-assassinatingtrump-press-conference/

35 See: http://www.thegatewaypundit.com/2016/08/expert-analysis-finds-hillary-clintons-recentseizures-sign-brain-damage/

36 See: http://www.thegatewaypundit.com/2016/09/dental-expert-hillary-clinton-suffering-seriousgum-infection-immune-disorder/

37 See: https://www.facebook.com/563896500417731/posts/771473306326715

38 See: https://www.facebook.com/380251501985837/posts/1372925612718416 
Data Leaks. Hacks and leaks were certainly discussed online. All of the pro-Trump pages made mention of "Wikileaks," 39 a non-profit that aims to "open governments," which in that period had shared more of the leaked Podesta emails to its website. Of the three pro-Trump pages, 65 posts mentioned "Wikileaks" during the month leading up to the 8 November election, accounting on average for $2.75 \%$ of all posts during that period. Both the conservative- and liberal-leaning media outlets analysed made mention of "Wikileaks" in this timeframe too: the seven right-leaning pages mentioned "Wikileaks" 131 times, accounting for $2.72 \%$ of all posts made on average, whereas the left-leaning pages referenced it 47 times, or in just $0.46 \%$ of all posts. The pages for InfoWars, Sean Hannity, and Wake Up \& Reclaim America referenced "Wikileaks" on average more than the others, accounting for $44 \%$ of all mentions found.

\subsubsection{Pro-Trump Pages Constitute an Echo Chamber - A Like-Minded Community, which Shared Similar Content}

A manual categorization of pages based on names and content reveals that nearly all (94.1\%) of the Citizens for Trump network are right-leaning, pro-Trump pages, while $82.7 \%$ of those within the Eagle Rising network are. In the Wake Up \& Reclaim America network of over 5,000 pages, a sample of 1,000 pages, representing $18.8 \%$ of the total, revealed that $67.8 \%$ of these were right-leaning, pro-Trump pages covering topics reflected in Trump's campaign rhetoric, such as pro-Christian, anti-Muslim, pro-military, pro-police, anti-immigration, and pro-life views.

As noted earlier, the three pro-Trump pages shared more alternative media sources than mainstream links in the month leading up to the 2016 election. Of those links shared to the pro-Trump pages and pointing to the conservative- and liberal-leaning pages also analysed, most were from either Fox or Breitbart. The page Eagle Rising shared none of the 14 media pages analysed, and the 1,143 links posted between 7 October and 7 November 2016 pointed to just 14 websites, including eaglerising.com.

\subsubsection{Pro-Trump Pages Posted Across Multiple Websites Affected Google Search Returns}

A Google search of article titles posted on pro-Trump pages sheds some light on how such networks function. For example, Eagle Rising shared an article from the blog the blacksphere.net entitled "Hillary Clinton: Calls Blacks Professional Never Do Wells.” This post garnered 157 shares on Facebook.

39 See: https://wikileaks.org 
A Google search using the article's exact title returned the original post, as well as several nearly exact reprints on other sites, with some linking back to The Blacksphere article. A search for The Blacksphere returned 734 results, including posts from rightwingnews.com, teapartytribune.com, and thegatewaypundit.com. Some of these links were posted by other users in comment sections and online forums, and Sharescount ${ }^{40}$ suggested the URL was shared 12,500 times across social networks. The article was also picked up by online trend aggregators like Trendolizer, ${ }^{41}$ indicating the efforts to spread this content had some impact. The apparent domination of these sites' content among first pages of Google returns may create an impression that Hilary Clinton has a clear bias against African Americans.

\subsubsection{Followers of Pro-Trump Pages Were Encouraged to Action}

All three pro-Trump pages encouraged their audiences to participate in spreading content and voting for Trump. As rates of follower shares demonstrated, Citizens for Trump and Eagle Rising were more successful than Wake Up \& Reclaim America, likely since they asked followers to share and spread messages more often.

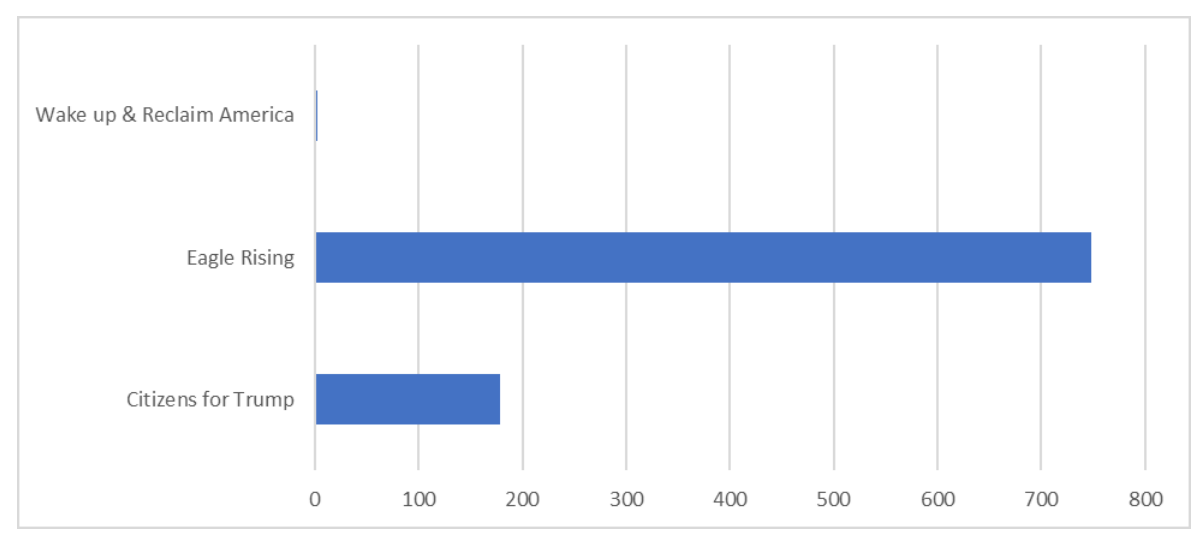

Figure 8.2: Average shares on posts by page.

40 See: https://sharescount.com/

41 See: http://bit.ly/2q9RYHs 
Depending on one's own echo chamber, the size of pro-Trump networks might come as a surprise. To some media pundits, Trump rode to the White House on a wave of fringe support (Coppins, 2015) - but that would be a mistake, as analysis of the networks shows.

Each of the networks were visualised using Gephi, presenting a total of 5,416 nodes with 100,208 edges between them. To put that into perspective, similar data pulls were made on two media page groups. The three pro-Trump pages had 16.3 times more nodes and 55.86 times more edges than the liberal-leaning media group.

Each network contained a considerable percentage of pages that have selfcategorized on Facebook as "Community," but also "Public Figure," "Politician" and some form of "News/Media” (See Figure 8.3).

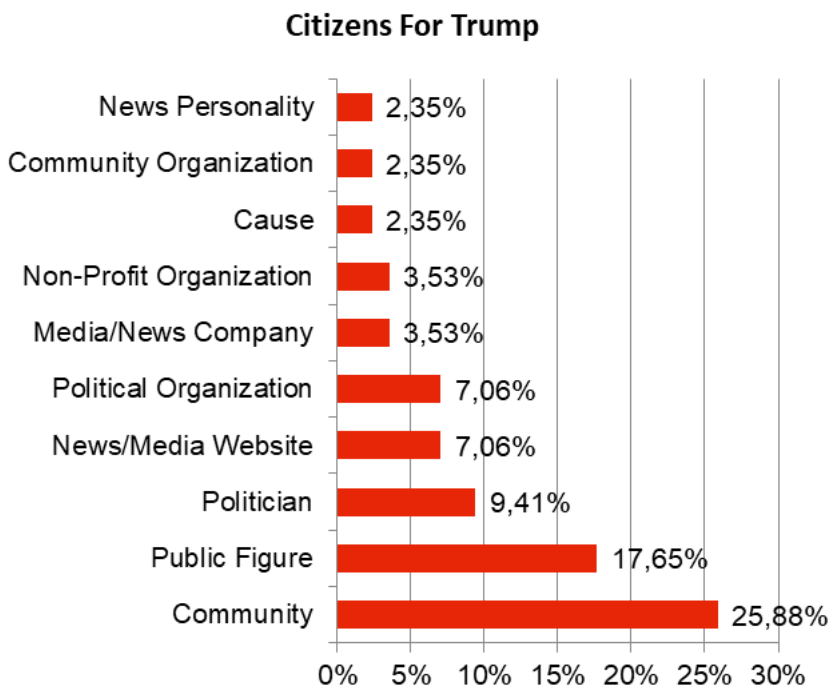

Figure 8.3: Facebook page categories selected by pages within pro-Trump page like network.

The pro-Trump network was then analysed using Gephi (Figure 8.4). Additional statistical analysis was conducted, using Modularity, which identifies the various communities within a network, marked in the data visualization below by colours. The pro-Trump network wasn't just bigger in comparison; it was also more closely integrated between pages with an Average Weighted Degree of 18.502 compared to that of the conservative-leaning media group at 9.01 or the liberal-leaning at 5.404 (the higher the number, the greater the average number of edges that touch a node in the network). 


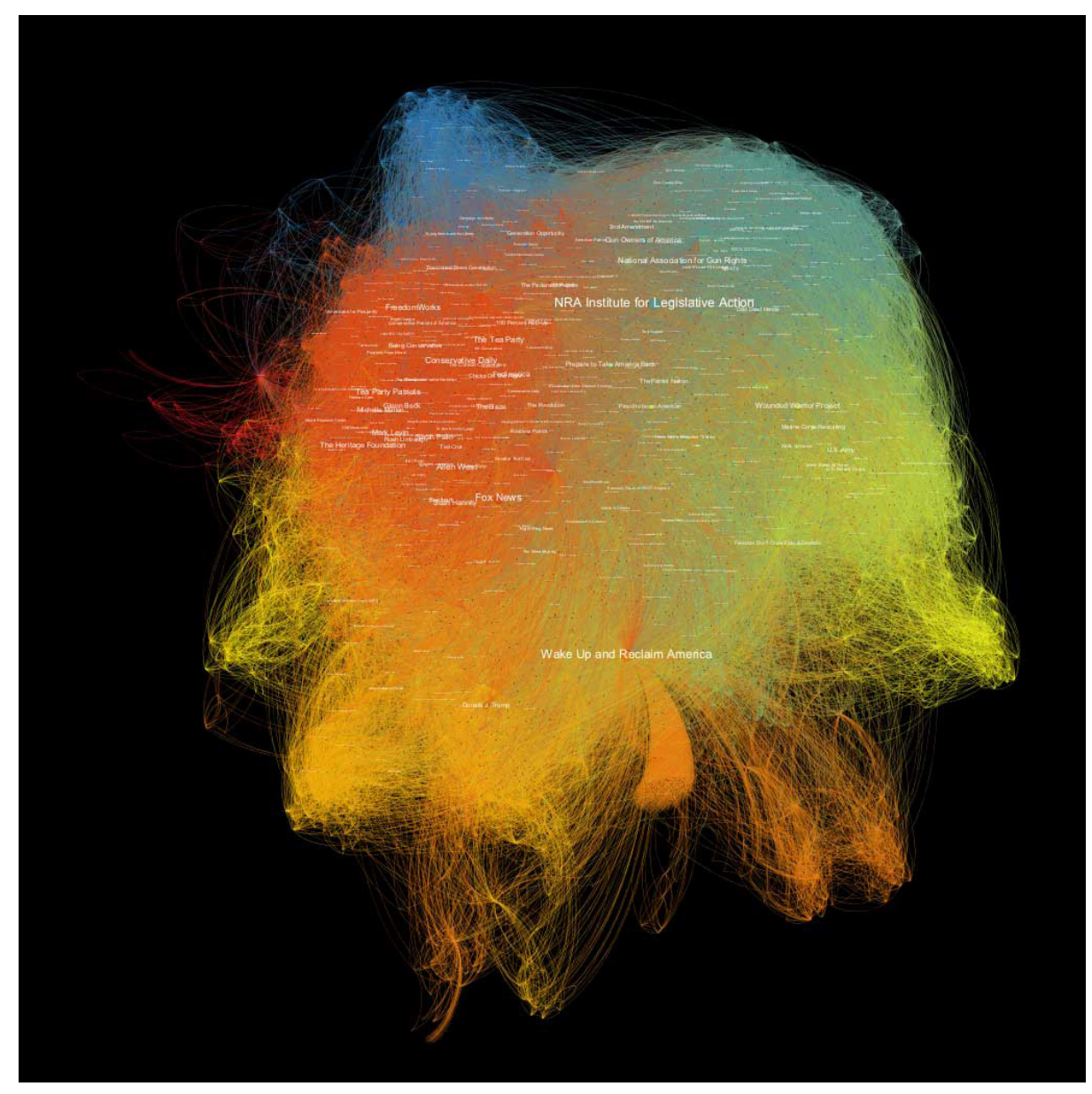

Figure 8.4: Three pro-Trump Facebook page like networks.

Pages liking each other demonstrate a possible channel for the spread of information. To investigate further, Netvizz was used to pull all posts made by each page from 7 October to 7 November 2016. These posts where analysed using Excel to count the mentions of specific terms (such as Clinton, Trump, and Wikileaks), how many posts were shared from other accounts, and what web domains were shared to the page, for example. The same investigative process was then applied to analysing the two media page groups.

Around one-third of the posts made by Wake Up \& Reclaim America (34.1\%) and Citizens for Trump (28.7\%) were shares from other Facebook accounts or pages, indicating community-like behaviour on these two pages. 


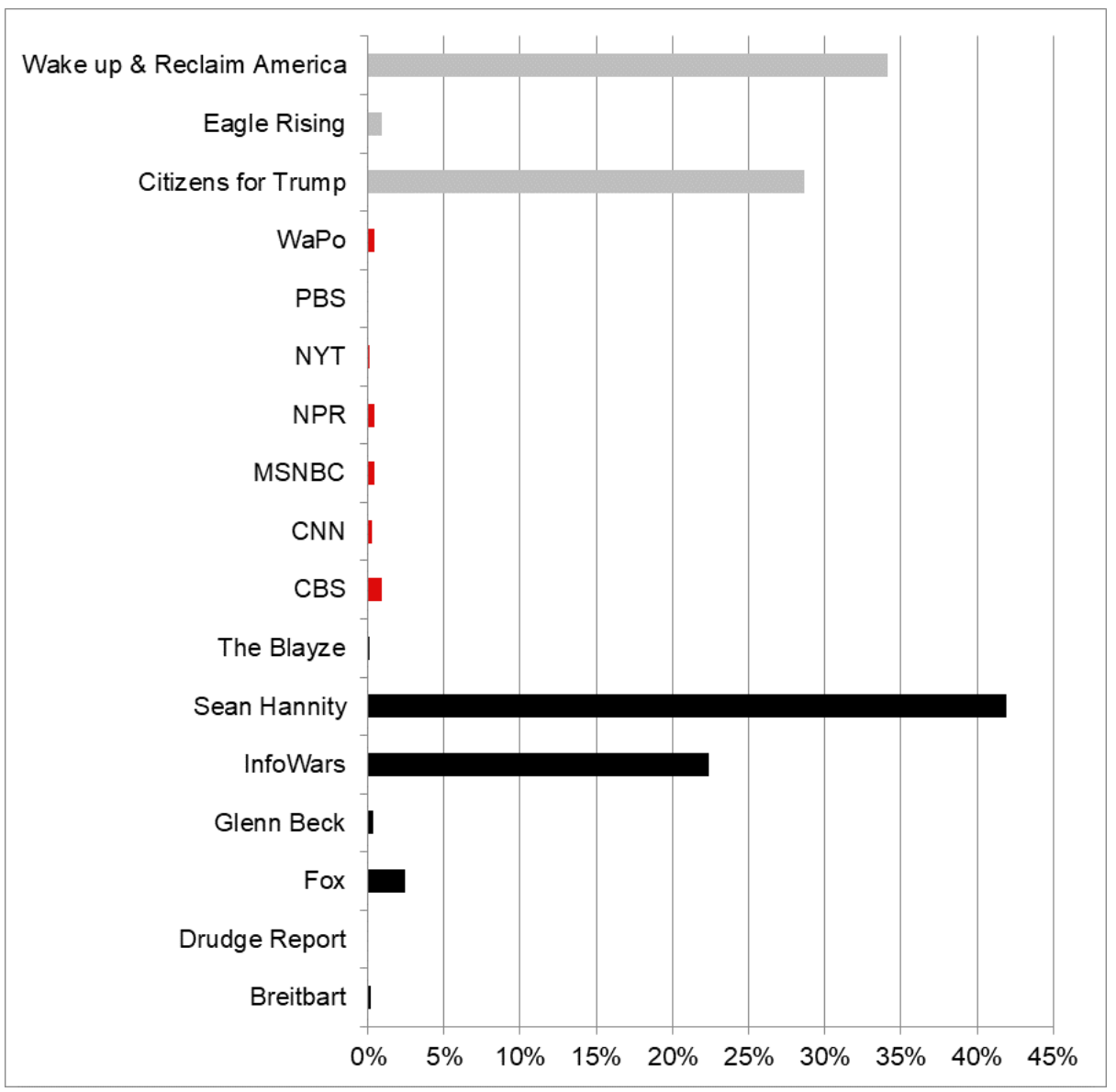

Figure 8.5: Number of posts shared from other Facebook pages or accounts.

Some pages, such as Occupy Libtards, ${ }^{42}$ enjoyed repeated shares to Wake Up \& Reclaim America, including The Deplorables. ${ }^{43}$ This Facebook group has 472,297 Members (as of 18 April 2017) and takes its name from a comment made by Hillary Clinton during the election about Trump supporters.

These pro-Trump pages are not operating in isolation. Of note, as bigger nodes in the pro-Trump Page Like network visualisation are Fox News, Sean Hannity, The Blaze, and Glenn Beck (see the darker orange community in the upper left of the

42 See: https://www.facebook.com/Occupy-Libtards-5-670970859684203/

43 See: https://www.facebook.com/groups/309472556081534/ 
network) - not to mention the NRA Institute for Legislative Action and The Heritage Foundation (Figure 8.6).

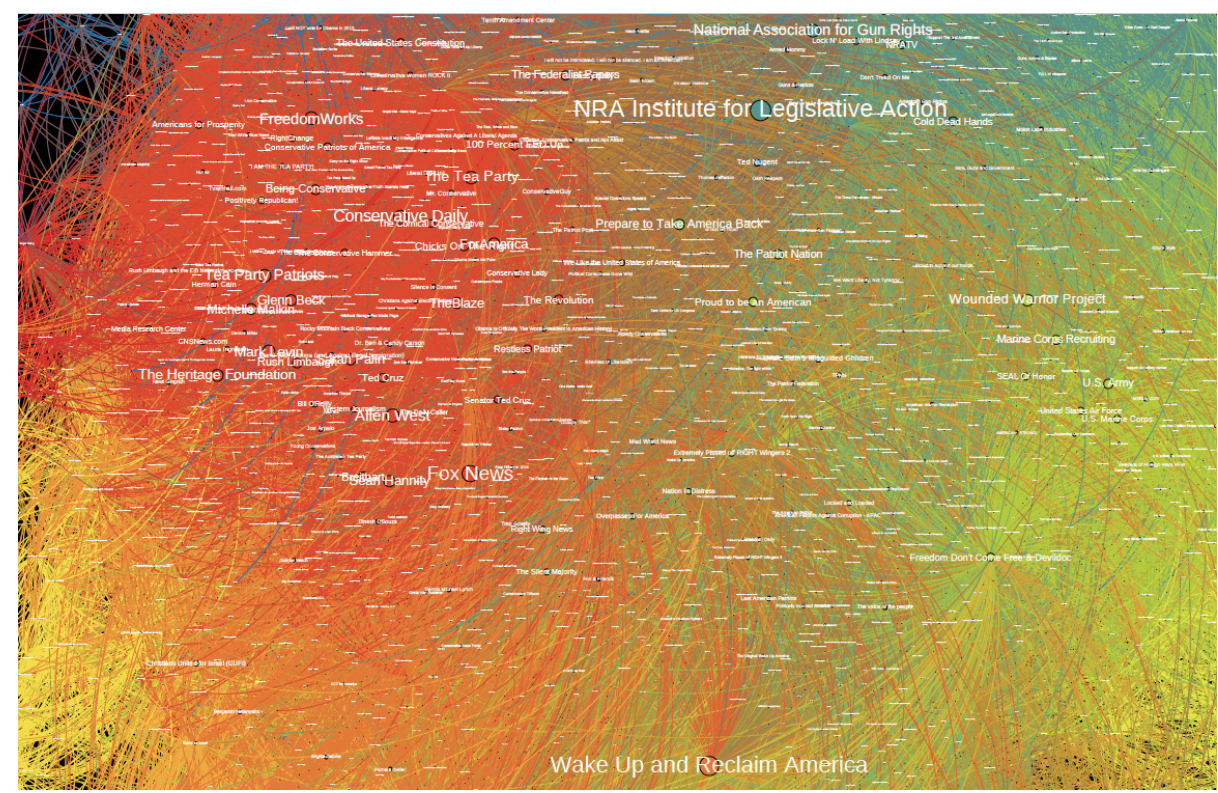

Figure 8.6: Zoomed in screenshot of pro-Trump Facebook page like network using Gephi.

Beyond the official political campaign Facebook pages, hundreds if not thousands of other pages pumped content supporting Trump to sympathetic users of that social network. Indeed, within the Wake Up \& Reclaim America network, 207 page names contain the word "Trump" - with many more that are pro-Trump that do not, making them much more difficult to track. Together, these Facebook pages support each other with reciprocal Page Likes and sharing of posts, while also mobilizing users to not just spread the message but also support Trump. In so doing, these online communities are also tapping into bigger organisations, such as media outlets, lobby groups, and think tanks - hinting at a much more systemic participatory propaganda effort.

\subsubsection{Pro-Trump Pages Heavily Engage with Media Outlets}

The pro-Trump Pages certainly followed right-leaning media outlets, as can be identified in the Page Like networks visualised above and featuring Fox News and Sean Hannity, among others. 
The liberal-leaning media group, visualised in Figure 8.7, comprised seven almost entirely independent communities. The visualisation below uses Gephi's stronger gravity function to keep the communities closer together for ease of viewing; however, they are not linked so closely in reality. What's more, the Facebook pages tend to be grouped into 'ego networks,' meaning any given media outlet tends to only like pages related to that network, such as its own TV shows or journalists.

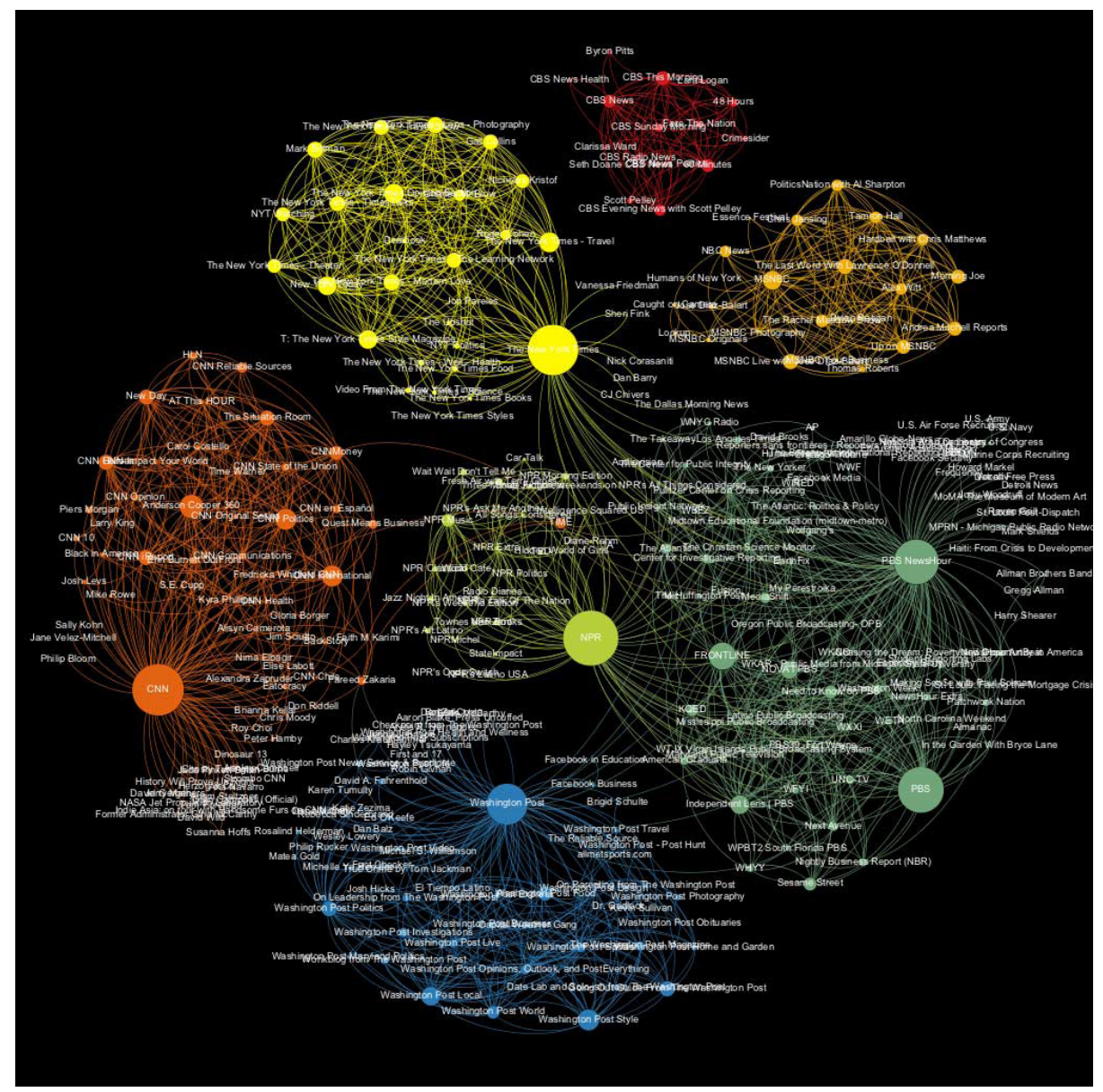

Figure 8.7: Left-leaning media Facebook page like (or “ego") network.

The conservative-leaning media group is quite different (Figure 8.8). The massive Infowars community dominates the visualisation, represented here below by the large yellow section, running into the Alex Jones network in blue, which comes with 
it. ${ }^{44}$ While nodes connect the Infowars monolith to Fox, the key connector page is Judge Andrew Napolitano. This is interesting in itself, as in past analysis of media Facebook Page Like networks, Fox stood out from outlets such as the BBC for its connecting to personalities, both their own journalists as well as US politicians, suggesting that some media outlets aren't just covering the news, but engaging directly with the subjects making the news (Wanless, 2015). This form of engagement could be considered alarming, if the notion of impartial news is accepted as crucial to a functioning democracy.

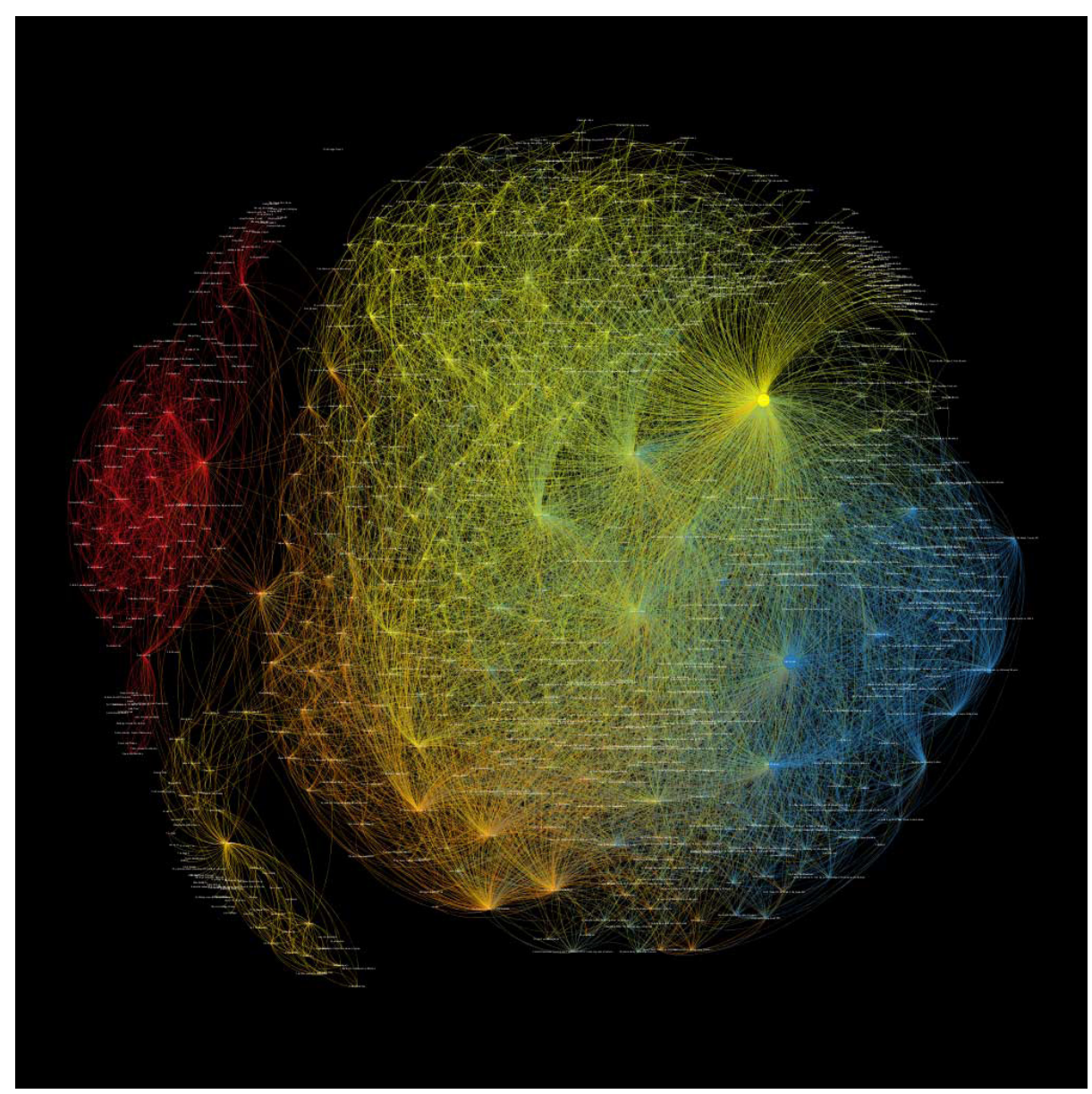

Figure 8.8: Right-leaning media page like networks.

44 Since then, Facebook has banned Alex Jones and Infowars blog from its pages. 
When these two media groups are combined with the pro-Trump network (Figure 8.9), the liberal-leaning outlets become islands unto themselves almost entirely disconnected (the blue communities at the bottom left), while the conservativeleaning media are absorbed into the overall community, and as noted above, in some cases becoming influential nodes.

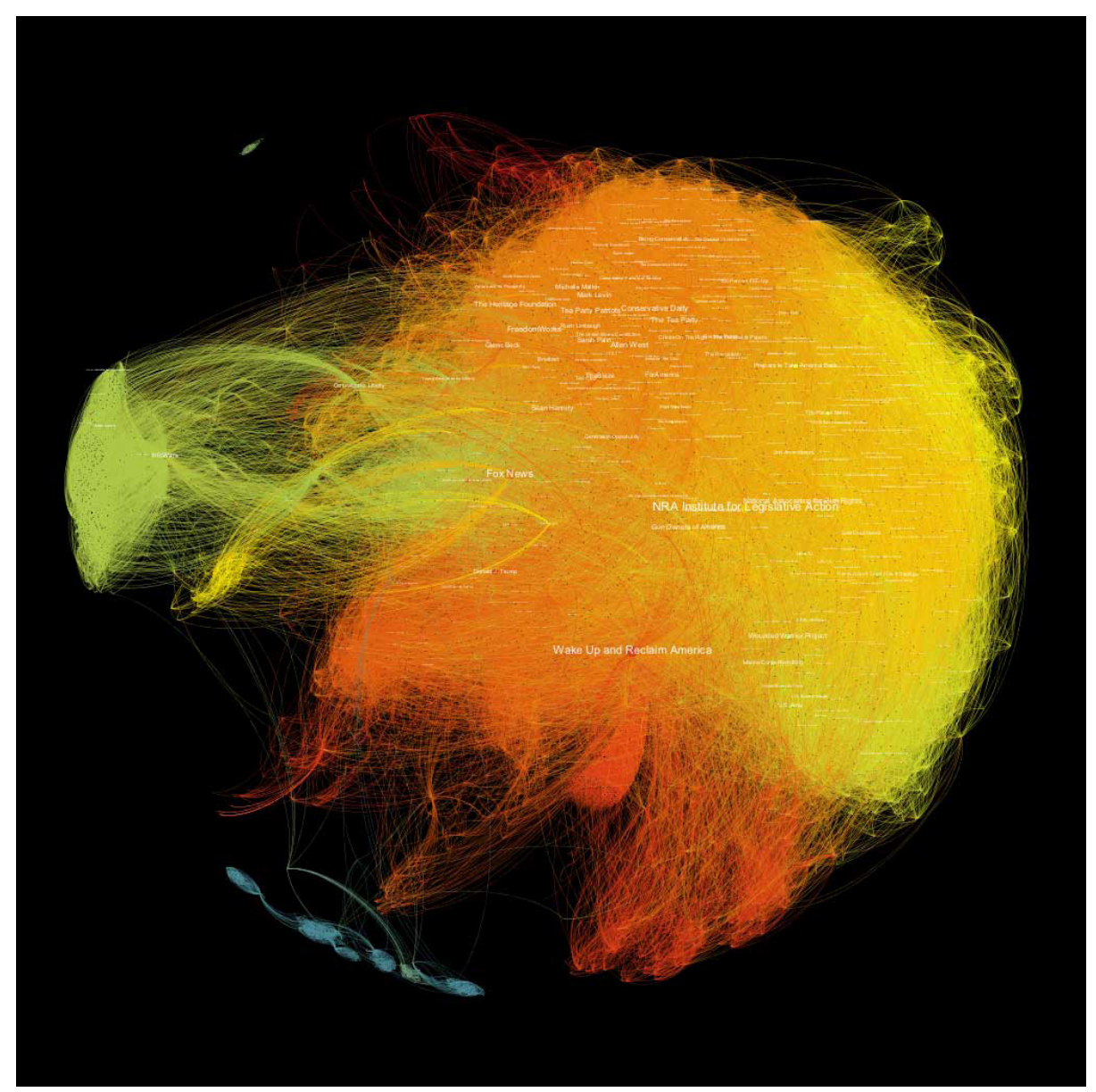

Figure 8.9: All Facebook page like networks combined.

In short, the conservative-leaning media network is more of an ecosystem that stretches beyond news outlet borders, blending into each other and pages beyond just media and journalists, into communities. 


\subsubsection{Pro-Trump Pages in a Participatory Propaganda Model}

While the analysis presented above is based on a very limited number of pages, the degree of engagement and inter-connectivity, both inside the network and with supportive media, demonstrate the existence of a systematic and coordinated attempt to influence the US voters to support the Trump campaign. All but two of the critical tactics identified in the participatory propaganda model were used by Trump supporters to achieve this goal, including sharing provocative content (fake news, memes, and data leaks), feeding such content into an echo chamber, reposting the same content, encouraging followers to do the same, and connecting with media and larger organisations supportive of Trump. The only two critical elements missing were hyper-targeted audience analysis (Step 1) and monitoring and evaluation (Step 7), as these activities are typically conducted through in-house research during a campaign and are not traceable through open sources. However, Cambridge Analytica has openly claimed to have used such tactics for the Trump campaign (Nix, 2016).

\subsection{Conclusion: Participatory Propaganda in Liberal Democracies}

As this chapter demonstrates, the organized deployment of various emerging technological and manipulative techniques in a digital era creates conditions for the emergence of an interactive form of engagement online where followers (target audience) are drawn into participating in the creation and spread of persuasive messaging. The example of the Trump 2016 presidential election campaign was used to demonstrate how these new tactics were deployed in combination with traditional media coverage to draw a considerable online following. This follower engagement constitutes a qualitatively more enhanced form of propaganda that is much more 'invasive' in nature - not to mention potentially very dangerous for liberal democracies, especially if cases of foreign interference in the electoral processes, such as the alleged Russian influence on the 2016 US election results, continue to mount.

As internet penetration rates in democratic countries surpasses $80 \%,{ }^{45}$ with many others in tow, nearly half of those populations finished high school before the web was even invented. ${ }^{46}$ As of 2015, 21\% of American survey respondents indicated they were online "almost constantly" (Perrin, 2015), and by the end of the first quarter

45 For more data, see 2016 CIRA report for Canada, the 2016 Office for National Statistics report for UK, and the 2017 Pew Research Center report for the USA.

46 Similar models of participatory propaganda have been identified through subsequent research on the 2017 U.K. general election (https://lageneralista.com/anti-establishment-blues-2017-u-k-election/) and Canadian political Facebook pages (https://lageneralista.com/polarising-politics-in-canada-afacebook-study/). 
in 2016, the average American was consuming 10:39 hours (Nielsen, 2016) of media across devices each day. Unlike radio and television before it, the internet has people constantly connected to information. Americans are at the vanguard of these changes - and as such are among the most vulnerable populations to information warfare, be it in the form of participatory propaganda, social engineering or cyber-attacks.

With such levels of exposure to a constant barrage of information, the ability of any one individual to discern its veracity and relevance in a broader context of daily life is constantly challenged. Furthermore, the effects of continuous online exposure on individual mental health or general perceptions of the world are still too poorly understood, and as such, are not yet part of mainstream knowledge or incorporated into national education curriculums at the level required to cope. The negative and long-lasting repercussions of such limited understanding are perhaps nowhere as serious as in national politics.

In 2014, the World Economic Forum listed "the spread of misinformation online" as one of the top ten trends facing the world (WEF, 2014). By 2016, Reporters Without Borders declared that we "have reached the age of post-truth, propaganda, and suppression of freedoms - especially in democracies" (2017). As demonstrated, modern propagandists have a considerable arsenal of methods at their disposal to manipulate populations, influence their opinions or engage them in active propagation of the desired content that go well beyond the creation and distribution of 'fake news' alone. Unfortunately, the tools and methods discussed in this article can be used by savvy propagandists everywhere, regardless of their political clout or country of provenance. What perhaps stands out most in this participatory propaganda model is its perpetuation. Through the use of online communities, such participatory propaganda campaigns run as long as the cause driving it matters to its members - or rather, those administrating such groups are able to produce content that engages and provokes followers. Finding ways to identify and measure engagement within these networks to understand the driving rationale, as opposed to blocking them, should be a priority for those studying liberal democracies.

\section{References}

Albright, J. (2016a, November 2016). \#Election2016: Propaganda-lytics \& Weaponized Shadow Tracking. [Online] Medium. Retrieved May, 11, 2017 from http://bit.ly/2pD3Q3M

Albright, J. (2016b, November 18). The \#Election2016 Micro-Propaganda Machine. [Online] Medium. Retrieved December, 29, 2016 http://bit.ly/2qYWvi]

Allcott, H. \& Gentzkow, M. (2017). Social Media and Fake News in the 2016 Election. The National Bureau of Economic Research. [Online] NBER Working Paper No. 23089. Retrieved May, 11, 2017 from http://www.nber.org/papers/w23089

Ambled, N. \& Bui, T. (2011). Harnessing the Influence of Social Proof in Online Shopping: The Effect of Electronic Word of Mouth on Sales of Digital Microproducts. International Journal of Electronic Commerce, 16(2), 91-114. 
Bakshy, E., Messing, S., \& Adamic, L.A., (2015). Exposure to ideologically diverse news and opinion on Facebook. Science, 348(6239), 1130-1132.

Bastion M., Heymann S., \& Jacomy, M. (2009). Gephi: an open-source software for exploring and manipulating networks. In Proceedings of the third international conference on weblogs and social media, AAAI: May 2009. Retrieved January, 22, 2017 from https://bit.ly/2TLFPKZ

BBC. (2016, November 15). US Election 2016: Trump’s ‘hidden’ Facebook army. BBC. [Online] Retrieved January, 21, 2017 from http://bbc.in/2ftfkEF

Benkler, Y., Faris, R., Roberts, H., \& Zuckerman, E. (2017). Study: Breitbart-led right-wing media ecosystem altered broader media agenda. Columbia Journalism Review [Online]. Retrieved May, 11, 2017 from http://bit.ly/2ougMbz

Bernays, E. L. (1928). Propaganda. Reprint: Ig Publishing, 2004.

Bessi, A., \& Ferrara, E. (2016). Social bots distort the 2016 US Presidential election online discussion. First Monday, 21(11). Retrieved February, 23, 2017 from https://bit.ly/2W3fgNO

Bessi, A, Zollo, F, Del Vicario, M, Puliga M, Scala, A, Caldarelli, G. ... Quattrociocchi, W. (2016). Users Polarization on Facebook and YouTube. PLOS ONE 11(8). Retrieved February, 19, 2017 from https://bit.ly/2QziJCC

Blackmore, S. (2000). The Meme Machine (Vol. 25). Oxford Paperbacks.

Bos, L., Van der Brug, W., \& De Vreese, C. (2010). Media coverage of right-wing populist leaders. Communications, 35(2), 141-163.

Breitenbach, D. (2017, February 7). What goes on in a far-right Facebook filter bubble? [Online] Deutsche Welle. Retrieved May, 11, 2017 from http://bit.ly/2poWipi

Buckels, E. E., Trapnell, P. D., \& Paulhus, D. L. (2014). Trolls just want to have fun. Personality and Individual Differences,67, 97-102. Retrieved May, 11, 2017 from http://bit.ly/1jNliM0

Castronovo, R. (2014). Propaganda 1776: Secrets, Leaks, and Revolutionary Communications in Early America. Oxford and New York: Oxford UP.

Cheng, J., Bernstein, M., Danescu-Niculescu-Mizil, C., \& Leskovec, J. (2017). Anyone Can Become a Troll: Causes of Trolling Behaviour in Online Discussions. In Proceedings of the 2017 ACM Conference on Computer Supported Cooperative Work and Social Computing (pp. 1217-1230). [Online] Retrieved May, 11, 2017 from http://bit.ly/2jZY4ub

Chmielewski, D. (2016, November 12). White supremacists urge trolling Clinton supporters to suicide. USA Today. [Online] Retrieved January, 21, 2017 from https://usat.ly/2fGtBOW

CIRA.ca (2016). Internet use in Canada. [Online] Retrieved November, 16, 2017 from https://bit. ly/2omFfkP

Cohen, R. (2017, February 20). Humanity in the Age of Al. The Huffington Post. [Online] Retrieved March, 20, 2017 from http://huff.to/2q5ZPrP

Connolly, K., Chrisafis, A., McPherson, P., Kirchgaessner, S., Haas, B., Phillips, D., Hunt, E., \& Safi, M. (2016, December 2). “Fake news: an insidious trend that's fast becoming a global problem”. The Guardian. [Online] Retrieved January, 21, 2017 from http://bit.ly/2gvuCJC

Coppins, M. (2015, November 27). How Donald Trump courted the right-wing fringe to conquer the GOP. The Washington Post. [Online] Retrieved May, 11, 2017 from http://wapo.st/2r9dVXo

Democracy Now. (2016, October 3). Clinton Tape: Sanders Supporters “Living in Their Parents' Basement”. Democracy Now. [Online] Retrieved January, 21, 2017 from http://bit.ly/2q6vBVj

Del Vicario, M., Bessi, A., Zollo, F., Petroni, F., Scala, A., Caldarelli, G. ... Quattrociocchi, W. (2016). The spreading of misinformation online. In Proceedings of the National Academy of Sciences, 113(3), 554-559. doi: 10.1073/pnas.1517441113

Dhami, M. K. (2011). Behavioural Science Support for JTRIG'S Effects and Online HUMINT Operations. The Intercept. [Online] Retrieved December, 29, 2016 from http://bit.ly/1TQrLZs

Dreyfus, E. (2017, January 20). Secret Facebook Groups are the Trump Era's Worst, Best Echo Chamber. Wired. [Online] Retrieved January, 21, 2017 from http://bit.ly/2jGtkNt 
Ellul, J. (1965). Propaganda: The Formation of Men's Attitudes, Trans. Konrad Kellen \& Jean Lerner. New York: Vintage Books.

Epstein, R. \& Robertson, R. E. (2015). The search engine manipulation effect (SEME) and its possible impact on the outcomes of elections. In Proceedings of the National Academy of Sciences, 112(33), E4512-E4521.

Frank, T. (2016, October 31). Forget the FBI cache; the Podesta emails show how America is run. The Guardian. [Online] Retrieved January, 13, 2017 from http://bit.ly/2eN30Pk

Facebook.com. (2017a). How does News Feed decide which stories to show? [Online] Retrieved January, 21, 2017 from http://bit.ly/2r6YXAY

Facebook.com. (2017b). How News Feed Works. [Online] Retrieved January, 21, 2017 from https://bit. ly/1wTf4MN

Finnegan, W. (2016, June 23). “Donald Trump and the 'Amazing' Alex Jones”. The New Yorker. [Online] Retrieved May, 11, 2017 from http://bit.ly/28QSd1a

Frankovic, K. (2016, December 27). Belief in conspiracies largely depends on political identity. [Online] YouGov. Retrieved January, 13, 2017 from http://bit.ly/2irRrfS

Garrison, W. C. (1999). Information Operations and Counter-Propaganda: Making a Weapon of Public Affairs. Carlisle Barracks, PA: Army War College.

Gallucci, N. (2016, December 5). A pizza shop patron is fighting back against the \#Pizzagate trolls. [Blog] Mashable. Retrieved January, 13, 2017 from http://on.mash.to/2r9oF89

Garrett, R. K. \& Weeks, B. E. (2013) The Promise and Peril of Real-Time Corrections to Political Misperceptions. In Proceedings of the 2013 Conference on Computer Supported Cooperative Work and Social Computing (pp. 1047-1058). [Online] Retrieved January, 13, 2017 from https:// bit.ly/2KcpwAM

Google.com (2017). How Search Works. [Online] Retrieved January, 21, 2017 from http://bit. ly/1zZneEO

Grömping, M. (2014). 'Echo Chambers' Partisan Facebook Groups during the 2014 Thai Election. Asia Pacific Media Educator, 24(1), 39-59.

Gruzd, A. \& Roy, J. (2014). Investigating political polarization on Twitter: A Canadian perspective. Policy \& Internet, 6(1), 28-45.

Gruzd, A. \& Tsyganova, K. (2015). Information Wars and Online Activism During the 2013/2014 Crisis in Ukraine: Examining the Social Structures of Pro-and Anti-Maidan Groups. Policy \& Internet, $7(2), 121-158$.

Hern, A. (2016, September 23). Oculus Rift founder Palmer Luckey spends fortune backing pro-Trump 'shitposts'. The Guardian. [Online] Retrieved January, 21, 2017 from http://bit.ly/2d5WX6q

Hsu, H, (2016, October 4). The Dank Memes that are 'Disrupting' Politics. The New Yorker. [Online] Retrieved December, 29, 2016 from http://bit.ly/2pCokZr

Irwin, W. (1919). An Age of Lies: How the Propagandist Attacks the Foundation of Public Opinion. Sunset 43 (December), 56-66.

Jowett, G. S. \& O'Donnell, V. (2015). Propaganda \& Persuasion. $6^{\text {th }}$ ed. Thousand Oaks, CA: Sage. P 7 Kabin, B. (2013, September 23). New York Cracks Down on Companies That Buy Fake Online Reviews, Entrepreneur. [Online] Retrieved December, 29, 2016 from http://bit.ly/2rOyDvq

Kang, C. (2016, November 21). Fake News Onslaught Targets Pizzeria as Nest of Child-Trafficking. The New York Times. [Online] Retrieved January, 13, 2017 from http://nyti.ms/2iB2s24

Katalenas, D. (2016, July 16). Join the US Freedom Army. LinkedIn User Post. [Online] Retrieved May, 11, 2017 from http://bit.ly/2r99cov

Kollanyi, B. \& Howard, P. N. (November 2016). Bots and Automation over Twitter during the U.S. Election. Data Memo. [Online] Retrieved January, 8, 2017 from http://politicalbots.org/?p=787 Lapowsky, I. \& Marshall, A. (2017, January 3). Ford's US Expansion is a Victory for Trump's Trolling Tactics. Wired. [Online] Retrieved January, 22, 2017 from http://bit.ly/2ixfWKZ 
Lasswell, H. D. (1934). World Politics and Personal Insecurity, reprinted in H. D. Lasswell, C. E. Merriamand T. V. Smith, A Study of Power (Glencoe: Free Press, 1950).

Lasswell, H. (1948). The Structure and Function of Communication in Society. The Communication of Ideas. In Bryson, L. (Ed.), The Communication of Ideas (pp. 37-51). New York: Institute for Religious and Social Studies.

Lazitski, O. (2014). Media Endarkenment: A Comparative Analysis of 2012 Election Coverage in the United States and Russia. American Behavioral Scientist, 58(7), 898-927.

Lippman, W. (1922). Public Opinion. (2012). Courier Corporation.

Lotan, G. (2016, November 22). Fake News Is Not the Only Problem. Points. [Online] Retrieved March, 20, 2017 from http://bit.ly/2qzAA1U

Maheshwari, S. (2017, January 18). 10 Times Trump Spread Fake News. The New York Times. [Online] Retrieved January, 22, 2017 from http://nyti.ms/2jBM9C4

Moloney, K. (2006). Rethinking public relations: PR propaganda and democracy (2nd ed.). Routledge.

Marantz, A. (2016, October 31). "Trolls For Trump: Meet Mike Cernovich, the meme mastermind of the alt-right,” The New Yorker. [Online] Retrieved December, 29, 2016 from http://bit.ly/2f9w9Fe

Marlin, R. (2011). Propaganda and the Ethics of WikiLeaks. Global Media Journal: Australian Edition, 5(1), 1-8.

Marlin, R. (2013). Propaganda and the Ethics of Persuasion. Broadview Press.

Mathew, G. (2017). Behind the Scenes of Behavioral Advertising. Kissmetrics. [Online] Retrieved May, 11, 2017 from http://bit.ly/XJ6DtZ

McClure, B. (2016). Discovering the Discourse of Internet Political Memes. In Adult Education Research Conference 2016 Conference Proceedings. [Online] Retrieved February, 12, 2017 from https://newprairiepress.org/aerc/2016/roundtables/12

Mitchell, A., Gottfried, J., Kiley, J., \& Matsa, K. E. (2016, October 21). Political Polarization \& Media Habits. Pew Research Centre. [Online] Retrieved December, 31, 2016 from http://pewrsr. $\mathrm{ch} / 1 \mathrm{tlHemf}$

Monbiot, G. (2011, February 11). The need to protect the internet from 'astroturfing' grows ever more urgent. The Guardian. [Online] Retrieved December, 29, 2016 from http://bit.ly/2r7DDdY

Moore, A. (2015). Conspiracies, Conspiracy Theories and Democracy. Political Studies Review, 16(1), 2-12

Moz.com (2017). External Links. [Online] Retrieved May, 11, 2017 from http://bit.ly/1NEfEuo

Mustafaraj, E. \& Metaxas, P. T. (2010). From obscurity to prominence in minutes: Political speech and real-time search. In Web Science Conference, 26-27 April 2010. Raleigh, NC: USA. [Online] Retrieved January, 25, 2017 from https://bit.ly/2Mj1836

Nielsen. (2016). The Total Audience Report: Q1 2016. [Online] Retrieved May, 11, 2017 from http://bit. ly/293jm5l

Nix, A. (2016, September 27). Power of Big Data and Psychographics [Video]. Retrieved December, 29, 2016 from http://bit.ly/2gD8FbL

Offman, C. (2016, October 15). Donald Trump seems to be campaigning to be Troll-in-Chief. The Globe and Mail. [Online] Retrieved January, 22, 2017 from https://tgam.ca/2r15]v1

Reference (Leak). In Oxford English Dictionary 2017. [Online] Retrieved November, 10, 2017 from https://en.oxforddictionaries.com/definition/leak

Pennycook, G., Cannon, T. D., \& Rand, D. G. (2017). Prior Exposure Increases Perceived Accuracy of Fake News. Journal of Experimental Psychology, 147(12), 1865-1880. Retrieved May, 11, 2017 from http://bit.ly/2r6X9YI

Perrin, A. (2015, December 8). One-fifth of Americans report going online 'almost constantly'. Pew Research Center. [Online] Retrieved May, 11, 2017 from http://pewrsr.ch/1M0ZFl0

Pew Research Centre. (2016a, June 22). Partisanship and Political Animosity in 2016. [Online] Retrieved December, 31, 2016 from http://pewrsr.ch/28WYkm 
Pew Research Centre. (2016b, November 10). Social Media Update. [Online] Retrieved November, 1, 2017 from http://pewrsr.ch/2nU4zMm

Pew Research Centre. (2017). Internet/Broadband Fact Sheet. [Online] Retrieved November, 16, 2017 from https://pewrsr.ch/2kQtkrM

Plouffe, D. (2010). The Audacity to Win: How Obama Won and How We Can Beat the Party of Limbaugh, Beck, and Palin. Updated ed. Penguin Books.

Renner, N., (2017, January 30). Memes trump articles on Breitbart's Facebook page. Colombia Journalism Review. [Online] Retrieved May, 11, 2017 from http://bit.ly/2pCf3Rs

Reporters Without Borders. (2017). 2017 World Press Freedom Index - tipping point. [Online] Retrieved May, 11, 2017 from http://bit.ly/2pyXh61

Rieder, B. (2013, May). Studying Facebook via data extraction: the Netvizz application. In Proceedings of the 5th Annual ACM Web Science Conference (pp. 346-355). ACM.

Ross, S. T. (2002). Understanding propaganda: The epistemic merit model and its application to art. Journal of Aesthetic Education, 36(1), 16-30.

Schreckender, B. (2017, March/April) World War Meme. Politico. [Online] Retrieved May, 11, 2017 from http://politi.co/2INQpvN

Scott, J. (1988). Social network analysis. Sociology, 22(1), 109-127.

Sheets, P., Bos, L., \& Boomgaarden, H. G. (2016). Media cues and citizen support for right-wing populist parties. International Journal of Public Opinion Research, 28(3), 307-330.

Silver, N. (2015, July 20). Donald Trump Is The World's Greatest Troll. [Blog] FiveThirtyEight. Retrieved January, 22, 2017 from http://53eig.ht/2r7BD5q

Silverman, C. (2015). Lies, Damn lies, and viral content. How news websites spread (and debunk) online rumors, unverified claims, and misinformation. [Online] Tow Center for Digital Journalism. Retrieved January, 22, 2017 from https://bit.ly/2YV487b

Silverman, C, Strapagiel, L, Shaban, H, Hall, E, \& Singer-Vine, J. (2016, October 20). Hyperpartisan Facebook Pages Are Publishing False And Misleading Information At An Alarming Rate. Buzzfeed. [Online] Retrieved January, 21, 2017 from http://bzfd.it/2poeH5C

Solon, O. (2017, 27 October). Russia's RT Reveals Twitter's Pitch to Sell Millions of Dollars in 2016 Election Ads. The Guardian. [Online] Retrieved November, 1, 2017 from http://bit.ly/2ycyh9a

Solon, 0. \& Levin S., (2016, December 16). How Google's search algorithm spreads false information with a right-wing bias. The Guardian. [Online] Retrieved January, 21, 2017 from http://bit. ly/2gSL7PJ

Thompson, A. (2016, December 8). Parallel narratives: Clinton and Trump supporters really don't listen to each other on Twitter, MIT Media Lab Electome project, VICE. [Online] Retrieved December, 29, 2016 from http://bit.ly/2poU0GC

Trump, D. (2016, 4 July). Dishonest media is trying their absolute best to depict a star in a tweet as the Star of David rather than a Sheriff's Star, or plain star! [Post] Twitter. Retrieved November, 1, 2017 from http://bit.ly/2xJrKP5

Turcotte, J., York, C., Irving, J., Scholl, R. M, \& Pingree, R. J., (2015). News recommendations from social media opinion leaders: Effects on media trust and information seeking. Journal of Computer-Mediated Communication, 20, 520-535. doi.org/10.1111/jcc4.12127

U.K. Office for National Statistics. (2016). Internet users in the UK: 2016. Statistical Bulletin. [Online] London: Office for National Statistics. Retrieved November, 16, 2017 from https://bit. $\mathrm{ly} / 2 \mathrm{eCVxzH}$

Wall Street Journal. (2016). Blue Feed, Red Feed: See Liberal Facebook and Conservative Facebook, Side by Side Retrieved January, 22, 2017 from http://graphics.wsj.com/blue-feed-red-feed/

Wanless, A. (2015). You've Got a Friend in News. [Blog] La Generalista. Retrieved November, 1, 2017 from https://lageneralista.com/youve-got-a-friend-in-news/

Wanless, A. (2016). Facebook and the U.S. Elections. [Blog] La Generalista. Retrieved November, 1, 2017 from https://lageneralista.com/facebook-stats/ 
Weedon, J., Nuland, W., \& Stamos, A. (2017). Information Operations and Facebook. [Online] Facebook. Retrieved May, 11, 2017 from http://bit.ly/2000S9s

WEF. (2013). Outlook on the Global Agenda 2014. [Online] World Economic Forum. Retrieved May, 11, 2017 from at http://bit.ly/2q8Ulqy

Williams, P. (2016, May 25). Guccifer, Hacker Who Says He Breached Clinton Server, Pleads Guilty. NBC News. [Online] Retrieved January, 21, 2017 from http://nbcnews.to/1szUR3X

Wodak, R. (2013). Right-wing populism in Europe: politics and discourse. A\&C Black

Woolley, S. C. \& Howard, P. N. (2018). (Eds). Computational propaganda: political parties, politicians, and political manipulation on social media. Oxford: Oxford University Press 